ISSN 2072-6694

www.mdpi.com/journal/cancers

Review

\title{
The Many Faces of Wnt and Pancreatic Ductal Adenocarcinoma Oncogenesis
}

\section{Colin D. Weekes ${ }^{1, *}$ and Robert A. Winn ${ }^{2,3}$}

1 Division of Medical Oncology, Department of Medicine, University of Colorado Cancer Center, University of Colorado Denver Anschutz Medical Campus, 12801 E. $17^{\text {th }}$ Avenue, Aurora, CO 80045, USA

2 Division of Pulmonary Sciences and Critical Care Medicine, Department of Medicine, University of Colorado Cancer Center, University of Colorado Denver Anschutz Medical Campus, 12605 E. $16^{\text {th }}$ Avenue, Aurora, CO 80045, USA; E-Mail: robert.winn@ucdenver.edu

3 Denver Veteran's Affairs Medical Center, 1055 Clermont Street, Denver, CO 80220, USA

* Author to whom correspondence should be addressed; E-Mail: colin.weekes@ucdenver.edu; Tel.: +1-303-724-0295; Fax: +1-303-724-3892.

Received: 8 August 2011; in revised form: 23 August 2011 / Accepted: 15 September 2011 / Published: 21 September 2011

\begin{abstract}
Pancreatic ductal adenocarcinoma (PDAC) remains amongst the most lethal human cancers. PDAC is characterized by the tumor mass containing a paucity of malignant cells in association with a large desmoplastic reaction comprised of a variety of stromal components. Sporadic PDAC oncogenesis occurs as a result of the sequential acquisition of genetic aberrations occurring in core genetic pathways. Unfortunately, the average PDAC contains a large number of genetic aberrations that are not uniform between individual cancers. The interplay between the complex genetics and stromal component may represent a significant barrier to the development of effective therapy for this disease and ultimately be an important factor in PDAC lethality. The Wnt pathway has been identified as a one of the common pathways undergoing genetic alterations in PDAC. Wnt is a complex signal transduction pathway utilizing both a $\beta$-catenin dependent (canonical) and $\beta$-catenin independent (noncanonical) signals to affect a wide array of intracellular events. Wnt signal transduction is an integral component of pancreas organogenesis promoting the expansion and development of the exocrine pancreas. Pancreatic cancer may utilize the Wnt signaling pathway in concert with other signaling pathways such as notch
\end{abstract}


during tumorigenesis. This review will focus on the role of Wnt signal transduction in pancreatic cancer biology.

Keywords: pancreatic ductal adenocarcinoma; Wnt; Frizzled; K-ras; $\beta$-catenin; stroma and angiogenesis

\section{Introduction}

Pancreatic ductal adenocarcinoma (PDAC) remains amongst the most lethal of human cancers. In 2010 approximately 43,140 individuals were diagnosed with PDAC and 36,800 patients died from the disease [1]. Many of these patients have advanced disease at diagnosis [2]. Unfortunately, despite an increased understanding of pancreatic cancer oncogenesis there has been limited improvement in therapeutic options available to these patients.

\section{Pancreatic Cancer Oncogenesis}

PDAC is distinguishable from most other epithelial tumors in that the tumor mass is comprised predominantly of a large desmoplastic reaction. Approximately $2-10 \%$ of PDAC is a result of hereditary syndromes $[3,4]$. Genetic and histologic analysis of PDAC has defined a sequential set of genetic abnormalities occurring in sporadic PDAC that coincide with the development of preneoplastic lesions known as Pancreatic Intraepithelial Neoplasms (PanIN) [5]. PanIN stage has been demonstrated to correlate with increasing mutational frequency and diversity [6]. Activating mutations in KRAS $\left(K R A S^{G 12 D}, K R A S^{G 12 V}, K R A S^{G 12 R}\right)$ occur in upwards of $85 \%$ of PDAC and can be recognized in $15-40 \%$ of PanIN I lesions $[7,8]$. PanIN stage 3 lesions are associated with an increased frequency of K-ras mutations as well as the acquisition of p53 and SMAD mutations [5,9]. A genetic mouse model (GEMM), in which the K-ras activating mutation (K-ras ${ }^{G 12 D}$ ) is placed under the control of pancreas early developmental genes: pancreatic and duodenal homeobox $1(P d x-1)$ or p48 (also known as Ptfla), recapitulates PanIN formation and PDAC observed in humans [10,11]. Interestingly, the addition of p53 mutation to that of K-ras results in the development of sporadic liver metastasis in these mice [12]. Combined these observations demonstrate the sufficiency of K-ras as a central initiator of PDAC oncogenesis in the context of subsequent genetic events that modulate PDAC oncogenesis. Sporadic PDACs harbor a minimum of 60 genetic abnormalities on average involving 12 core genetic pathways [13]. The Wnt pathway represents of these core genetic pathways. Ultimately, the interaction between PDAC complex genetics and the desmoplastic tumor cell microenvironment may be a large determinant of the poor response to currently utilized therapeutic agents to treat this disease.

\section{Wnt Signal Transduction}

The Wnt signal transduction pathway is an important embryonic signaling pathway that is required for proliferation, morphogenesis and differentiation of several organs, including the pancreas [14]. The human Wnt signaling pathway is comprised of 19 Wnt ligands that bind to the frizzled family of 
receptors and co-receptors [15]. Wnt binding to frizzled results in the activation of two desperate signaling pathways known as the $\beta$-catenin dependent (canonical) and the $\beta$-catenin independent (non-canonical) pathways. Activation of these intracellular pathways occurs in the context of the co-receptor that forms a complex with frizzled upon Wnt binding. As such, LRP5/6-frizzled complex formation results in $\beta$-catenin dependent pathway activation; whereas, formation of the receptor tyrosine kinase-like orphan receptor (ROR) ROR1/2-frizzled complex promotes $\beta$-catenin independent pathway activation [16]. Recruitment of disheveled to a juxtaposed position of the $\beta$-catenin phosphorylation site promotes $\beta$-catenin stabilization by preventing glycogen synthase kinase-3 (GSK-3) mediated phosphorylation of $\beta$-catenin. The subsequent inactivation of the cytoplasmic protein complex (comprised of AXIN, adenomatous polyposis coli (APC), GSK-3) that promotes proteosomal degradation of $\beta$-catenin allows stabilized unphosphorylated $\beta$-catenin accumulate in the cytoplasm. $\beta$-catenin can then translocate into the nucleus and bind the transcription factors TCF/LEF resulting in target gene activation [15]. Alternatively, cytoplasmic $\beta$-catenin is an integral component of adherent junctions and forms complexes with epithelial-cadherin (E-cadherin) to promote intracellular adhesions $[17,18]$. In contrast, the $\beta$-catenin independent pathway functions to regulate protein kinase $\mathrm{C}$ (PKC), calcium mobilization and planar cell polarity $[19,20]$. The $\beta$-catenin dependent pathway has primarily been evaluated in terms of PDAC oncogenesis; however, WNT5a, which classically stimulates the $\beta$-catenin independent pathway, is commonly deranged in PDAC supporting the role for $\beta$-catenin independent signaling in PDAC tumorigenesis [21,22].

\section{Wnt Signal Transduction and Pancreatic Cancer Oncogenesis}

Mutations in genes encoding for the regulatory proteins of the $\beta$-catenin dependent pathway that may function as initiating genetic lesions, as is seen in colon cancer, are rare in PDAC [23]. However, $\beta$-catenin accumulation in both the cytoplasmic and nuclear cellular fraction is observed in a small subset of patients and correlates with PanIN grade and the development of PDAC [24-26]. The finding that the combined Wnt and notch signaling pathways are amongst the most common mutated genetic pathways altered in patients with pancreatic cancer suggest it's importance to pancreatic cancer tumorigensis. These pathways appear to be interlinked in that notch signaling functions as a negative regulator $\beta$-catenin dependent signaling both in pancreas organogenesis and oncogenesis as will be discussed in a subsequent section. GEMMs have been utilized to interrogate the functional role of Wnt signaling pathway in pancreatic cancer oncogenesis. The findings of these studies have been recently been elegantly reviewed by Morris et al. [27]. In short, placing the expression of constitutively active $\beta$-catenin with pdx-1 or ptf1 promoter; thereby localizing allelic expression to the pancreas, failed to promote PanIN or malignant tumor formation (Table 1) [28-31]. However, in vivo modeling of pancreatitis in the mouse has led to very unique observations eliciting a novel role for KRAS and Wnt in acinar cell plasticity. In this situation, acinar cells possess the ability to undergo acinar to ductal metaplasia (ADM) [32-34]. This phenomenon allows for the expeditious repair of the pancreas in response to cellular injury, as is observed under conditions of chronic pancreatitis. Chronic pancreatitis has been directly linked to the development of PanINs and PDAC in a KRAS-driven GEMM [35]. Interestingly, enforced expression of high levels of KRAS in acini induces ADM [36]. As such, KRAS mediated ADM may be a crucial component of PDAC development particularly in response to chronic 
injury or inflammation $[35,37,38]$. In this setting, $\beta$-catenin may serve a similar role as to that in pancreas development. $\beta$-catenin is stabilized in response to caerulein induced chronic pancreatitis but is turned off simultaneously to the induction of KRAS mediated ADM. In contrast, forced $\beta$-catenin stabilization inhibits ADM, PanIN and PDAC formation, resulting in the development of abnormal ductal structures. These observations further support the inability of $\beta$-catenin to initiate pancreas cancer and support the concept that the primary role of $\beta$-catenin signaling in PDAC oncogenesis may be in the maintenance and proliferation of PDAC cells.

Table 1. $\beta$-catenin Associated Genetic Mouse Models of Pancreas Cancer.

\begin{tabular}{|c|c|c|}
\hline$\beta$-catenin & Phenotype & Ref. \\
\hline $\mathrm{Pdx} 1-\mathrm{Cre}^{\text {Late }} ; \mathrm{Ctnn} 1^{\text {exon3/+ }}$ & $\begin{array}{l}\text { Acinar cell proliferation and postnatal } \\
\text { pancreatomegaly without tumor formation. }\end{array}$ & [29] \\
\hline Pdx1-Cre ${ }^{\text {Late }} ; \mathrm{Apc}^{\text {flox/flox }}$ & $\begin{array}{l}\text { Acinar cell proliferation and postnatal } \\
\text { pancreatomegaly without tumor formation. }\end{array}$ & [30] \\
\hline p48-Cre; Ctnnb1 ${ }^{\text {exon3/+ }}$ & $\begin{array}{l}\text { Development of tumors similar to human solid } \\
\text { pseudopapillary tumors. }\end{array}$ & {$[31]$} \\
\hline $\begin{array}{l}\text { p48-Cre;Ctnnb } 1^{\text {exon } 3 /+} ; \\
\text { LSL-Kras }^{G 12 D}\end{array}$ & $\begin{array}{l}\text { Development of tumors similar to intraductal tubular } \\
\text { tumors. }\end{array}$ & {$[31]$} \\
\hline
\end{tabular}

\section{WNT5a Signaling and Pancreatic Cancer Biology}

WNT5a is a classic $\beta$-catenin independent (non-canonical) Wnt that is commonly deranged in pancreatic cancer [21]. Conflicting data exist with respect to its expression in pancreatic cancer. One report demonstrates that Wnt5a expression is downregulated in PDAC cells in comparison to normal tissue [39]. In contrast, other reports demonstrate increased Wnt5a expression in PanIN and PDAC compared to normal counterparts [22]. One explanation in the observe differences in these reports may be a reflection of sampling and number specimens analyzed. Wnt5a may also function in a paracrine function in PDAC. Analysis of PDAC stroma in comparison to the stroma of chronic pancreatitis demonstrates overexpression of Wnt5a in PDAC stroma [40]. Interestingly, coculture experiments with pancreatic cancer cell line and fibroblast suggest that pancreatic cancer cells may induce fibroblast Wnt5a secretion by soluble factors. A potential mechanism may be tumor growth factor- $\beta$ induced CUTL1 mediated Wnt5a transcription [22]. These observations were associated with the WNT5a regulation of $\beta$-catenin dependent function. The characterization of the co-receptors involved in these observations was not performed. However, these data would support recent observations that individual Wnt proteins may function to activate both $\beta$-catenin dependent and independent pathways depending on the co-receptor that is complexed with frizzled upon its binding. In this context, WNT5a promotes pancreatic cancer migration, proliferation and invasiveness. The role of $\beta$-catenin independent regulation of PDAC progression and metastasis remains unclear.

\section{Hypoxia, Angiogenesis and Wnt Signaling}

The physiologic parameters under which PDAC exist is an important consideration when contemplating the role of a signal transduction pathway in pancreatic adenocarcinoma oncogenesis. How might oxygen tension impact PDAC tumorigenesis in the context of Wnt pathway function? 
Lesson from pancreas development may apply to PDAC tumorigenesis as both events occur in relative anoxic conditions. Prior to E13.5 pancreas organogenesis occurs under relative hypoxic conditions, which in turn promotes hypoxia inducible factor- $1 \alpha$ (HIF-1 $\alpha$ ) mediated induction of Notch signal transduction [41,42]. Notch in turn, promotes the initial proliferation of undifferentiated endocrine cells from multipotent progenitor cells $[43,44]$. In contrast, hypoxia results in both HIF-1 $\alpha$ dependent and independent inhibition of $\mathrm{Wnt} / \beta$-catenin signal transduction $[45,46]$. Beyond day 13.5, neovascularization of the pancreas results in a relative normoxic state which turns off notch signaling in exocrine pancreas cells allowing for the proliferative expansion of the exocrine pancreas in response to $\mathrm{Wnt} / \beta$-catenin signaling $[47,48]$. These observations mimic the tight regulation of $\beta$-catenin in terms of the temporal relation between its expression and the generation of ADM induced PanIN and PDAC formation. Similarly, HIF-1 $\alpha$ is associated with ptf-1a expression and notch pathway activation during acute pancreatitis in mice, which in turn is associated with ADM [49]. The notch pathway regulates epithelial to mesenchymal transition (EMT) as well as promotes the conversion of high-grade PanIN lesions into PDAC in KRAS mutated cells $[50,38,51]$. Inhibition of both the notch and Wnt/ $\beta$-catenin signalling pathways can inhibit pancreas cancer cell growth. Thus the interplay between these to embryonic pathways may have a significant role in pancreatic cancer biology. Recently orthotopic models of hypoxic tumor cells from patient-derived xenografts demonstrated increased proliferative capacity and the development of metastases. Selective inhibition of hypoxic cells has been associated with decreased invasiveness and metastatic potential ultimately translating into improved survival in orthotopic mouse models [52,53]. Ultimately, oxygen tension has a significant role in PDAC tumorigenesis by a wide array of mechanisms.

Angiogenesis is an important tumor response to hypoxia. The $\beta$-catenin independent pathway may be an integral component of the development functional vasculature as the tumor mass grows. WNT5a has been demonstrated to be responsible for capillary sprouting and branching, which are important components of forming mature vessels during angiogenesis [54]. It may be in this context that WNT5a is overexpressed in pancreas tumor stroma. The restoration of normoxic conditions may directly suppress the aggressive phenotype of PDAC as outlined previously. In addition, treatment of pancreas cancer GEMM with the combination of a hedgehog inhibitor and gemcitabine resulted in tumor vasculature modulation, which in turn enhanced the effectiveness of DNA damaging cytotoxic chemotherapy [55]. Targeting WNT pathway along with hedgehog may be a represent a novel therapeutic strategy to effectively inhibit both pancreas cell tumorigenicity and angiogenesis to further improve the efficacy of gemcitabine-based chemotherapy. This strategy may overcome the apparent clinical inactivity of targeting angiogenesis in PDAC.

\section{Pancreas Cancer Stem Cells and Chemotherapy Resistance}

Pancreatic cancer stem cells (PCSC) have been identified at the tumor-stroma interface within human tumors. The significance of the localization of PCSCs within the pancreas tumor is exemplified by a prevailing hypothesis that stromal components of the tumor can provide appropriate signals to promote tumor cell EMT to promote the development of the stem cell population. These cells are marked by their ability to express cell surface markers CD133, CD24/CD44/ESA or by the functional expression of aldehyde dehydrogenase [56-59]. The PCSC represents a rare cell population of the 
malignant cells within a tumor mass [60]. The importance of this cell population lies in their ability undergo self-renewal whilst promoting tumor initiation. Self-renewal pathways such as hedgehog, notch and Wnt have been demonstrated to be integral components in the maintenance of cancer stem cell populations. Direct evidence for the function of these pathways in pancreas cancer remains to be fully characterized. However, pharmacologic inhibition of the hedgehog pathway abrogates PCSC tumorigenicity in vivo [61]. The interplay between these three pathways may also be very important for the maintenance of this population. Notch has recently been demonstrated to directly bind to $\beta$-catenin to inhibit its function by promoting $\beta$-catenin lysosomal sequestration and degradation in embryonic stem cells and colon cancer cells [62]. It remains to seen if this finding applies to cancer stem cells but represents an intriguing mechanism by which notch may directly negatively regulate Wnt function. This may be particularly germane to pancreatic cancer given the relationship between notch and Wnt in pancreas organogenesis described previously.

The innate resistance to chemotherapy may be the most clinically relevant function of cancer stem cells. These cells are often quiescent making them refractory to DNA damaging agents. The cancer stem cell population utilizes the ABC drug transporters that pump out chemotherapy. As such, gemcitabine refractory cells possess tumor-initiating properties. These cells also express the chemokine receptor CXCR4, which is an integral component of the ability of these cells to develop metastases in orthotopic models [56]. CXCR4 activation of $\beta$-catenin dependent signal transduction results in pancreatic cancer cell proliferation and invasion [63]. Interestingly, CXCR4 mediated signal transduction has been demonstrated to promote gemcitabine resistance in association with $\beta$-catenin expression [64]. Oncogenic forms of tyrosine kinase receptors such as c-met, which are expressed on the cellular surface of PCSCs, have been demonstrated to positively regulate $\beta$-catenin function $[65,66]$. Since these same receptors can stimulate survival pathways such as PI3-Kinase/mTOR and the mitogen activated protein kinase (MAPK) pathways, one could envisage that the PCSC niche may function to promote survival of the cancer stem cell during times of cellular stress such chemotherapy exposure. In contrast, the niche may also support EMT and cellular proliferation during favorable microenvironmental conditions to promote PCSC tumorigenicity. Given the role of the Wnt pathway in many of these functions, including the role of the $\beta$-catenin independent function in cellular polarization, targeting the Wnt pathway may represent a therapeutic strategy to inhibit pancreas cancer stem cell function at multiple levels.

\section{Conclusions}

In summary, the Wnt pathway is a multifaceted developmental signal transduction pathway controlling a multitude of cellular functions. It is under tight regulation both in pancreas development and pancreatic ductal adenocarcinoma oncogenesis. The exact role of this pathway in PDAC development remains to be fully elucidated and will ultimately be a study in systems biology as it also appears to integrate signals from secondary signal transduction pathways which may invariably contain genetic alterations. In addition, PDAC is comprised of many cellular components all of which play integral but incompletely understood roles in the overall progression of PDAC. Understanding the role of Wnt signaling in the context of these varied biologic events may ultimately result in improved therapeutic strategies for targeting this disease. 


\section{References}

1. American Cancer Society. Cancers Facts \& Figures 2010; American Cancer Society: Atlanta, GA, USA, 2010; Report No.: 1.

2. Maitra, A.; Hruban, R.H. Pancreatic cancer. Annu. Rev. Pathol. 2008, 3, 157-188.

3. Habbe, N.; Langer, P.; Sina-Frey, M.; Bartsch, D.K. Familial pancreatic cancer syndromes. Endocrinol. Metab. Clin. North Am. 2006, 35, 417-430.

4. Wescott, M.P.; Rustgi, A.K. Pancreatic cancer: Translating lessons from mouse models and hereditary syndromes. Cancer Prev. Res. 2008, 1, 503-506.

5. Wilentz, R.E.; Iacobuzio-Donahue, C.A.; Argani, P.; McCarthy, D.M.; Parsons, J.L.; Yeo, C.J.; Kern, S.E.; Hruban, R.H. Loss of expression of Dpc4 in pancreatic intraepithelial neoplasia: Evidence that DPC4 inactivation occurs late in neoplastic progression. Cancer Res. 2000, 60, 2002-2006.

6. Feldmann, G.; Geaty, R.; Hruban, R.H.; Maitra, A. Molecular genetics of pancreatic intraepithelial neoplasia. J. Hepatobiliary Pancreat. Surg. 2007, 14, 224-232.

7. Almoguera, C.; Shibata, D.; Forrester, K.; Martin, J.; Arnheim, N.; Perucho, M. Most human carcinomas of the exocrine pancreas contain mutant c-KRAS genes. Cell 1988, 53, 549-554.

8. Lohr, M.; Kloppel, G.; Maisonneuve, P.; Lowenfels, A.B.; Luttges, J. Frequency of KRAS mutations in pancreatic intraductal epithelial neoplasias associated with pancreatic ductal adenocarcinoma and chronic pancreatitis: A metanalysis. Neoplasia 2005, 7, 17-23.

9. Maitra, A.; Adsay, N.V.; Argani, P.; Iacobuzio-Donahue, C.; De Marzo, A.; Cameron, J.L.; Yeo, C.J.; Hruban, R.H. Multicomponent analysis of the pancreatic adenocarcinoma progression model using a pancreatic intraepithelial neoplasia tissue microarray. Mod. Pathol. 2003, 16, 902-912.

10. Hingorani, S.R.; Petricoin, E.F.; Maitra, A.; Rajapakse, V.; King, C.; Jacobetz, M.A.; Ross, S.; Conrads, T.P.; Veenstra, T.D.; Hitt, B.A.; et al. Preinvasive and invasive ductal pancreatic cancer and its early detection in the mouse. Cancer Cell. 2003, 4, 437-450.

11. Tuveson, D.A.; Shaw, A.T.; Willis, N.A.; Silver, D.P.; Jackson, E.L.; Chang, S.; Mercer, K.L.; Grochow, R.; Hock, H.; Crowley, D.; et al. Endogenous oncogenic KRAS ${ }^{\mathrm{G} 12 \mathrm{D}}$ stimulates proliferation and widespread neoplastic and developmental defects. Cancer Cell. 2004, 5, 375-387.

12. Morton, J.P.; Timpsona, P.; Karima, S.A.; Ridgway, R.A.; Athineos, D.; Doyle, B.; Jamieson, N.B.; Oien, K.A.; Lowy, A.M.; Brunton, V.G.; Frame M.C.; et al. Mutant p53 drives metastasis and overcomes growth arrest/senescence in pancreatic cancer. Proc. Natl. Acad. Sci. USA 2010, 107, 246-251.

13. Jones, S.; Zhang, X.; Parson, W.D.; Lin, J.C.; Leary, R.J.; Angenendt, P.; Mankoo, P.; Carter, H.; Kamiyama, H.; Jimeno, A.; et al. Core signaling pathways in human pancreatic cancer revealed by global genomic analysis. Science. 2008, 321, 1801-1806.

14. Clevers, H. Wnt/ $\beta$-catenin signaling in development and disease. Cell 2006, 127, 469-480.

15. MacDonald, B.T.; Tamai, K.; He, X. Wnt/ $\beta$-catenin signaling: components, mechanism and disease. Dev. Cell 2009, 17, 9-26.

16. Grumolato, L.; Guizhong, L.; Mong, P.; Mudbhary, R.; Biswas, R.; Arroyave, R.; Vijayakumar, S.; Economides, A.N.; Aaronson, S.A. Canonical and noncanonical Wnts use a common mechanism to activate completely unrelated coreceptors. Genes Dev. 2010, 24, 2517-2530. 
17. Gumbiner, B.M.; McCrea, P.D. Catenins as mediators of the cytoplasmic functions of cadherins. J. Cell Sci. 1993, 17, 155-158.

18. Jou, T.S.; Stewart, D.B.; Stappert, J.; Nelson, W.J.; Marrs, J.A. Genetic and biochemical dissection of protein linkages in the cadherin-catenin complex. Proc. Natl. Acad. Sci. USA 1995, 92, 5067-5071.

19. Kühl, M.; Sheldahl, L.C.; Park, M.; Miller, J.R.; Moon, R.T. The Wnt/Ca2+ pathway: A new vertebrate Wnt signaling pathway takes shape. Trends Genet. 2000, 16, 279-283.

20. Wallingford, J.B.; Mitchell, B. Strange as it may seem: The many links between Wnt signaling, planar cell polarity, and cilia. Genes Dev. 2011, 25, 201-213.

21. Schwartz, A.L.; Malgor, R.; Dickerson, E.; Weeraratna, A.T.; Slominski, A.; Wortsman, J.; Harii, N.; Kohn, A.D.; Moon, R.T.; Schwartz, F.L.; et al. Phenylmethimazole decreases toll-like receptor 3 and noncanonical WNT5a expression in pancreatic cancer and melanoma together with tumor cell growth and migration. Clin. Cancer Res. 2009, 15, 4114-4122.

22. Ripka, S.; Konig, A.; Buchholz, M.; Wagner, M.; Sipos, B.; Klöppel, G.; Downward, J.; Gress, T.; Michl, P. WNT5a - target of CUTL1 and potent modulator of tumor cell migration and invasion in pancreatic cancer. Carcinogenesis 2007, 28, 1178-1187.

23. Gerdes, B.; Ramaswamy, A.; Simon, B.; Pietsch, T.; Bastian, D.; Kersting, M.; Moll, R.; Bartsch, D. Analysis of $\beta$-catenin gene mutations in pancreatic tumors. Digestion 1999, 60, 544-548.

24. Al-Aynati, M.M.; Radulovich, N.; Riddell, R.H.; Tsao, M.S. Epithelial-cadherin and $\beta$-catenin expression changes in pancreatic intraepithelial neoplasia. Clin. Cancer Res. 2004, 10, 1235-1240.

25. Zeng, G.; Germinaro, M.; Micsenyi, A.; Monga, N.K.; Bell, A.; Sood, A.; Malhotra, V.; Sood, N.; Midda, V.; Monga, D.K.; Kokkinakis, D.M.; Monga, S.P. Aberrant Wnt/ $\beta$-catenin signaling in pancreatic adenocarcinoma. Neoplasia 2006, 8, 279-289.

26. Pasca di Magliano, M.; Biankin, A.V.; Heiser, P.W.; Cano, D.A.; Gutierrez, P.J.; Deramaudt, T.; Segara, D.; Dawson, A.C.; Kench, J.G.; Henshall, S.M.; Sutherland R.L.; et al. Common activation of canonical Wnt signaling in pancreatic adenocarcinoma. PLoS one 2007, 2, e1155.

27. Morris, J.P.; Wang, S.C.; Hebrok, M. KRAS, hedgehog, wnt and the twisted developmental biology of pancreatic ductal adenocarcinoma. Nat. Rev. Cancer 2010, 10, 683-695.

28. Kemler, R.; Hierholzer, A.; Kanzler, B.; Kuppig, S.; Hansen, K.; Taketo, M.M.; de Vries, W.N.; Knowles, B.B.; Solter, D. Stabilization of $\beta$-catenin in the mouse zygote leads to premature epithelial-mesemchymal transition in the epiblast. Development 2004, 131, 5817-5824.

29. Heiser, P.W.; Lau, J.; Taketo, M.M.; Herrera, P.L.; Hebrok, M. Stabilization of $\beta$-catenin impacts pancreas growth. Development 2006, 133, 2023-2032.

30. Strom, A.; Bonal, C.; Ashery-Padan, R.; Hashimoto, N.; Campos, M.L.; Trumpp, A.; Noda, T.; Kido, Y.; Real, F.X.; Thorel, F.; et al. Unique mechanisms of growth regulation and tumor suppression upon Apc inactivation I the pancreas. Development 2007, 134, 2719-2725.

31. Heiser, P.W.; Cano, D.W.; Landsman, L.; Kim, G.E.; Kench, J.G.; Klimstra, D.S.; Taketo, M.M.; Biankin, A.V.; Hebrok, M. Stabilization of $\beta$-catenin induces pancreas tumor formation. Gastroenterology 2008, 135, 1288-1300.

32. Carriere, C.; Young, A.L.; Gunn, J.R.; Longnecker, D.S.; Korc, M. Acute pancreatitis markedly accelerates pancreatic cancer progression in mice expressing oncogenic Kras. Biochem. Biophys. Res. Commun. 2009, 382, 561-565. 
33. Strobel, O.; Dor, Y.; Alsina, J.; Stirman, A.; Lauwers, G.; Trainor, A.; Castillo, C.F.; Warshaw, A.L.; Thayer, S.P. In vivo lineage tracing defines the role of acinar-to-ductal transdifferentiation in inflammatory ductal metaplasia. Gastroenterology 2007, 133, 1999-2009.

34. Siveke, J.T.; Lubeseder-Martellato, C.; Lee, M.; Sipos, B.; Nakhai, H.; Rad, R.; Zimber-Strobl, U.; Strobl, L.J.; Radtke, F.; Klöppel, G.; Schmid, R.M.; Siveke, J.T. Notch signaling is required for exocrine regeneration after acute pancreatitis. Gastroenterology 2008, 134, 544-555.

35. Guerra, C.; Collado, M.; Navas, C.; Schuhmacher, A.J.; Hernández-Porras, I.; Cañamero, M.; Rodriguez-Justo, M.; Serrano, M.; Barbacid, M. Pancreatitis-induced inflammation contributes to pancreatic cancer by inhibiting oncogene-induced senescence. Cancer Cell 2011, 19, 728-739.

36. Ji, B.; Tsou, L.; Wang, H.; Gaiser, S.; Chang, D.Z.; Daniluk, J.; Bi, Y.; Grote, T.; Longnecker, D.S.; Logsdon, C.D. Ras activity levels control the development of pancreatic diseases. Gastroenterology 2009, 137, 1072-1082.

37. Zhu, L.; Shi, G.; Schmidt, C.M.; Hruban, R.H.; Konieczny, S.F. Acinar cells contribute to the molecular heterogeneity of pancreatic intraepithelial neoplasia. Am. J. Pathol. 2007, 171, 263-273.

38. De La Oa, J.-P.; Emersonb, L.L.; Goodmana, J.L.; Froebea, S.C.; Illuma, B.E.; Curtisa, A.B.; Murtaugha, C.L. Notch and Kras reprogram pancreatic acinar cells to ductal intraepithelial neoplasia. Proc. Natl. Acad. Sci. USA 2008, 105, 18907-18912.

39. Crnogorac-Jurcevic, T.; Efthimiou, E.; Capelli, P.; Blaveri, E.; Baron, A.; Terris, B.; Jones, M.; Tyson, K.; Bassi, C.; Scarpa, A.; et al. Gene expression profiles of pancreatic cancer and stromal desmoplasia. Oncogene 2001, 20, 7437-7446.

40. Pilarsky, C.; Ammerpohl, O.; Sipos, B.; Dahl, E.; Hartmann, A.; Wellmann, A.; Braunschweig, T.; Löhr, M.; Jesnowski, R.; Friess, H.; et al. Activation of Wnt signaling in stroma from pancreatic cancer identified by gene expression profiling. J. Cell. Mol. Med. 2008, 12, 2823-2835.

41. Cejudo-Martin, P.; Johnson, R.S. A new notch in the HIF belt: How hypoxia impacts differentiation. Dev. Cell 2005, 9, 575-576.

42. Pear, W.S.; Simon, D.C. Lasting longer without oxygen: the influence of hypoxia on Notch signaling. Cancer Cell 2005, 8, 435-437.

43. Apelqvist, A.; Li, H.; Sommer, L.; Beatus, P.; Anderson, D.J.; Honjo, T.; Hrabe de Angelis, M.; Lendahl, U.; Edlund, H. Notch signaling controls pancreatic cell differentiation. Nature 1999, 400, 877-881.

44. Jensen, J.; Pederson, E.E.; Galante, P.; Hald, J.; Heller, R.S.; Ishibashi, M.; Kageyama, R.; Guillemot, F.; Serup, P.; Madsen, O.D. Control of endodermal endocrine development by Hes-1. Nat. Genet. 2000, 24, 36-44.

45. Kaidi, A.; Williams, A.C.; Paraskeva, C. Interaction between $\beta$-catenin and HIF-1 promotes cellular adaptation to hypoxia. Nat. Cell. Biol. 2007, 9, 210-217.

46. Funato, Y.; Michiue, T.; Asashima, M.; Miki, H. The thioredoxin-related redox-regulating protein nucleoredoxin inhibits Wnt- $\beta$-catenin signaling through disheveled. Nat. Cell. Biol. 2006, 8, 501-508.

47. Murtaugh, L.C.; Law, A.C.; Dor, Y.; Melton, D.A. $\beta$-catenin is essential for pancreatic acinar but not islet development. Development 2005, 132, 4663-4674. 
48. Wells, J.C.; Esni, F.; Boivin, G.P.; Aronow, B.J.; Stuart, W.; Combs, C.; Sklenka, A.; Leach, S.D. Lowy, A.M. Wnt/ $\beta$-catenin signaling is required for development of the exocrine pancreas. $B M C$ Dev. Biol. 2007, 7, 4.

49. Gomez, G.; Englander, E.W.; Wang, G.; Greeley, G.H., Jr. Increased expression of hypoxiainducible factor-1alpha, p48, and the Notch signaling cascade during acute pancreatitis in mice. Pancreas 2004, 28, 58-64.

50. Wang, Z.; Li, Y.; Kong, D.; Banerjee, S.; Ahmad, A.; Azmi, A.S.; Ali, S.; Abbruzzese, J.L.; Gallick, G.E.; Sarkar, F.H. Acquisition of epithelial-mesenchymal transition phenotype of gemcitabine-resistant pancreatic cancer cells is linked with activation of the notch signaling pathway. Cancer Res. 2009, 69, 2400-2407.

51. Mazur, P.K.; Einwächter, H.; Lee, M.; Sipos, B.; Nakhai, H.; Rad, R.; Zimber-Strobl, U.; Strobl, L.J.; Radtke, F.; Klöppel, G.; et al. Notch2 is required for progression of pancreatic intraepithelial neoplasia and development of pancreatic ductal adenocarcinoma. Proc. Natl. Acad. Sci. USA 2010, 107, 13438-13443.

52. Chang, Q.; Jurisica, I.; Do, T.; Hedley, D.W. Hypoxia predicts aggressive growth and spontaneous metastasis formation from orthotopically grown primary xenografts of human pancreatic cancer. Cancer Res. 2011, 71, 3110-3120.

53. Kizaka-Kondoh, S.; Itasaka, S.; Zeng, L.; Tanaka, S.; Zhao, S.; Takahashi, Y.; Keiko, S.; Hirota, K.; Semenza, G.L.; Hiraoka, M. Selective killing of hypoxia-inducible Factor-1-Active cells improves survival in a mouse model of invasive and metastatic pancreatic cancer. Clin. Cancer Res. 2009, 15, 3433-3441.

54. Masckauchan, T.N.; Agalliu, D.; Vorontchikhina, M.; Ahn, A.; Parmalee, N.L.; Li, C.M.; Khoo, A.; Tycko, B.; Brown, A.M.; Kitajewski, J. Wnt5a signaling induces proliferation and survival of endothelial cells in vitro and expression of MMP-1 and Tie-2. Mol. Biol. Cell 2006, 17, 5163-5172.

55. Olive, K.P.; Jacobetz, M.A.; Davidson, C.J.; Gopinathan, A.; McIntyre, D.; Honess, D.; Madhu, B.; Goldgraben, M.A.; Caldwell, M.E.; Allard, D.; et al. Inhibition of Hedgehog signaling enhances delivery of chemotherapy in a mouse model of pancreatic cancer. Science 2009, 324, 1457-1461.

56. Hermann, P.C.; Huber, S.L.; Herrler, T.; Aicher, A.; Ellwart, J.W.; Guba, M.; Bruns, C.J.; Heeschen, C. Distinct populations of cancer stem cells determine tumor growth and metastatic activity in human pancreatic cancer. Cell Stem Cell 2007, 1, 313-323.

57. Li, C.; Heidt, D.G.; Dalerba, P.; Burant, C.F.; Zhang, L.; Adsay, V.; Wicha, M.; Clarke, M.F.; Simeone, D.M. Identification of pancreatic cancer stem cells. Cancer Res. 2007, 67, 1030-1037.

58. Feldmann, G.; Dhara, S.; Fendrich, V.; Bedja, D.; Beaty, R.; Mullendore, M.; Karikari, C.; Alvarez, H.; Iacobuzio-Donahue, C.; Jimeno, A.; et al. Blockade of hedgehog signaling inhibits pancreatic cancer invasion and metastases: A new paradigm for combination therapy in solid cancers. Cancer Res. 2007, 67, 2187-2196.

59. Kim, M.P.; Fleming, J.B.; Wang, H.; Abbruzzese, J.L.; Choi, W.; Kopetz, S.; McConkey, D.J.; Evans, D.B.; Gallick, G.E. ALDH activity selectively defines an enhanced tumor-initiating cell population relative to CD133 expression in human pancreatic adenocarcinoma. PLoS one 2011, 6, e20636. 
60. Ishizawa, K.; Rasheed, Z.A.; Karisch, R.; Wang, Q.; Kowalski, J.; Susky, E.; Pereira, K.; Karamboulas, C.; Moghal, N.; Rajeshkumar, N.V.; Hidalgo, M.; et al. Tumor-initiating cells are rare in many human tumors. Cell Stem Cell 2010, 7, 279-282.

61. Jimeno, A.; Feldmann, G.; Suárez-Gauthier, A.; Rasheed, Z.; Solomon, A.; Zou, G.M.; Rubio-Viqueira, B.; García-García, E.; López-Ríos, F.; Matsui, W.; et al. A direct pancreatic cancer xenograft model as a platform for cancer stem cell therapeutic development. Mol. Cancer Ther. 2009, 8, 310-314.

62. Kwon, C.; Cheng, P.; King, I.N.; Andersen, P.; Shenje, L.; Nigam, V.; Srivastava, D. Notch post-translationally regulates $\beta$-catenin protein in stem and progenitor cells. Nat. Cell Biol. 2011, doi:10.1038/ncb2313.

63. Wang, Z.; Ma, Q.; Liu, Q.; Yu, H.; Zhao, L.; Shen, S.; Yao, J. Blockade of SDF-1/CXCR4 signalling inhibits pancreatic cancer progression in vitro via inactivation of canonical Wnt pathway. Br. J. Cancer 2008, 99, 1695-1703.

64. Singh, S.; Srivastava, S.K.; Bhardwaj, A.; Owen, L.B.; Singh, A.P. CXCL12-CXCR4 signalling axis confers gemcitabine resistance to pancreatic cancer cells: A novel target for therapy. Br. $J$. Cancer 2010, 103, 1671-1679.

65. Shah, A.N.; Summy, J.M.; Zhang, J.; Park, S.I.; Parikh, N.U.; Gallick, G.E. Development and characterization of gemcitabine-resistant pancreatic tumor cells. Ann. Surg. Oncol. 2007, 14, 3629-3637.

66. Danilkovitch-Miagkova, A.; Miagkov, A.; Skeel, A.; Nakaigawa, N.; Zbar, B.; Leonard, E.J. Oncogenic mutants of RON and MET receptor tyrosine kinases cause activation of the beta-catenin pathway. Mol. Cell Biol. 2001, 21, 5857-5868.

(C) 2011 by the authors; licensee MDPI, Basel, Switzerland. This article is an open access article distributed under the terms and conditions of the Creative Commons Attribution license (http://creativecommons.org/licenses/by/3.0/). 